\title{
As Culturas do Escrito expressas em um Livro de Registro de Entrada de Mercadorias (1967 - 1971)
}

\author{
Las Culturas del Escrito expresas en un Libro de Registro de Entrada de
} Mercaderías (1967-1971)

The Written Cultures expressed in a Book of Entry of Goods (1967 - 1971)

\author{
Lucas Gonçalves Soares ${ }^{1}$ \\ Larissa Lima Nascimento Costa ${ }^{2}$
}

\begin{abstract}
Resumo
O presente trabalho é o resultado de uma investigação que ocorreu a partir de uma análise em um livro de registro de entrada de mercadorias, sendo ele referente ao comércio do bisavô paterno do primeiro autor - José Francisco Meireles, este, por um longo período foi dono e gerenciou um comércio no interior do município de Canguçu, município localizado na região Sul do estado do Rio Grande do Sul. O livro corresponde ao período de 1967 a 1971. O objetivo geral do estudo consiste em analisar os registros encontrados no livro, refletindo sobre os usos da escrita e da Matemática por pessoas com pouco estudo, como era o caso do bisavô do primeiro autor, tendo cursado somente até a segunda série primária. Considerando a descrição dos registros contidos no livro e cálculos matemáticos desenvolvidos, esses revelam que estamos inseridos nas culturas do escrito independente de termos tido acesso à educação formal.
\end{abstract}

PALAVRAS-CHAVE: Culturas do escrito, práticas de escrita, livro de registro.

\section{Resumen}

El presente trabajo es el resultado de una investigación que ocurrió a partir de un análisis en un libro de registro de entrada de mercaderías, siendo él referente al comercio del bisabuelo paterno del primer autor José Francisco Meireles, éste, por un largo período fue dueño y gestionó un comercio en el interior del municipio de Canguçu, municipio ubicado en la región sur del estado de Rio Grande do Sul. El libro corresponde al período de 1967 a 1971. El objetivo general del estudio consiste en analizar los registros encontrados en el libro, reflejando sobre los usos de la escritura y de la Matemática por personas con poco estudio, como era el caso de bisabuelo del primer autor, habiendo cursado solamente hasta la segunda serie primaria. Considerando la descripción de los registros contenidos en el libro y cálculos matemáticos desarrollados, estos revelan que estamos insertos en las culturas del escrito independiente de haber tenido acceso a la educación formal.

PALABRAS CLAVE: Culturas del escrito, prácticas de escritura, libro de registro.

\footnotetext{
'Doutorando em Educação - UFPel; Grupo de pesquisa História da Alfabetização, Leitura, Escrita e dos Livros Escolares - HISALES/UFPel; Pelotas, Rio Grande do Sul, Brasil; luks_gs21@hotmail.com. Trabalho apresentado no III Encontro Humanístico Multidisciplinar e II Congresso Latino-Americano em Estudos Humanísticos Multidisciplinares, Jaguarão/RS, Brasil, 2017

${ }^{2}$ Ms. em Educação - UFPel. Professora Assistente da Universidade Federal do Pampa, campus Jaguarão/Rio Grande do Sul; lari.limacosta@gmail.com. Trabalho apresentado no III Encontro Humanístico Multidisciplinar e II Congresso Latino-Americano em Estudos Humanísticos Multidisciplinares, Jaguarão/RS, Brasil, 2017
} 


\begin{abstract}
The present work is the result of an investigation that occurred from an analysis in a book of entry of merchandise, being it refers to the commerce of the paternal great grandfather of the first author - José Francisco Meireles, this one, for a long period was owner and managed a trade within the municipality of Canguçu, a municipality located in the southern region of the state of Rio Grande do Sul. The book corresponds to the period from 1967 to 1971 . The general objective of the study is to analyze the records found in the book, reflecting on the uses of writing and mathematics by people with little study, as was the case of the first great great-grandfather, having only studied until the second primary series. Considering the description of the records contained in the book and mathematical calculations developed, these reveal that we are inserted in the writing cultures regardless of having had access to formal education.
\end{abstract}

KEYWORDS: Cultures of writing, writing practices, log book.

\title{
Introdução
}

Este artigo tem como objetivo principal analisar os usos da escrita no livro de registro de entrada de mercadorias, referente ao comércio do bisavô do primeiro autor do texto, José Francisco Meireles ${ }^{3}$, datado de 1967 a 1971. José Francisco foi uma pessoa influente e respeitada no interior do município de Canguçu na localidade do Santo Antônio, $3^{\circ}$ distrito ${ }^{4}$ embora tenha estudado somente até a segunda série primária, o que era comum na época, conforme afirma Galvão (2002): "Sabe-se, no entanto que, pelo menos até as primeiras décadas do século $\mathrm{XX}$, as taxas de analfabetismo chegavam a quase $70 \%$ da população com mais de 15 anos do país e eram muito baixos os índices de escolarização." (GALVÃO, 2002, p.116).

Mesmo assim, José Francisco tornou-se um exímio comerciante, proprietário de pousada e churrascaria ${ }^{5}$ na cidade de Pelotas, no período de 1953 a 1962, mais tarde, de uma casa comercial - denominada "Casa Comercial de secos e molhados Meireles" e também de um Salão de Baile "Salão Natal" - 1964 a 1986, aproximadamente. Ele deu nome a uma escola de Anos Iniciais $^{6}$ na localidade onde residia, para qual doou o terreno de sua construção. Na referida escola, a partir da data de sua fundação (1965), estudaram praticamente todos os moradores da comunidade, inclusive de meu pai, minha mãe, meus irmãos e eu. Ainda hoje, mesmo estando alocada em outro prédio, pois foi ampliada para atender todo o Ensino Fundamental. A Escola Municipal de Ensino Fundamental Francisco Meireles é referência na localidade e ainda atende familiares de José Francisco, suas trisa netas, sobrinhas do primeiro autor.

\footnotetext{
${ }^{3}$ Nascido em 11 de setembro de 1923, falecido em 12 de janeiro de 1992.

${ }^{4}$ Distante 73 quilômetros da sede do município.

${ }^{5}$ Não foi encontrado o nome de tal estabelecimento, somente o período que esteve em atividade.

${ }^{6}$ Escola Municipal de Ensino Fundamental incompleto José Francisco Meireles, fundada em abril de 1965, localizada na localidade do Santo Antônio, $3^{\circ}$ distrito de Canguçu, afastada 73 quilômetros da sede do município. Funcionava em um turno e a professora trabalhava com as 4 primeiras séries do Ensino Fundamental, ou seja, multisseriada.
} 
Propomos nesse texto a análise de um livro de Registro de Entrada de Mercadorias da Casa Comercial de Secos e Molhados Meireles, com data do primeiro registro em 3 de janeiro de 1967 e último em 12 de setembro de 1971.

O referido livro, no momento, está em nossa posse. Foi encontrado em uma caixa de brinquedos da sobrinha do primeiro autor, a mesma, reside na casa que serviu de sede para a Casa Comercial já mencionada. O suporte estava servindo para "brincar de escolinha" por ela e suas amigas, por esse motivo apresenta algumas rasuras e escritas que não são originais, o que não prejudicou de maneira significativa a análise realizada neste trabalho.

A motivação para realizar esse estudo deu-se por dois fatores: 1 - Por ser um material que de certa forma representa o passado da família do primeiro autor, que tem uma base voltada para o Comércio, sendo que, antes da geração do mesmo, outras três viviam do comércio e da plantação de arroz; 2 - Nossa curiosidade, enquanto pesquisadores, de buscar através dessa análise entender como antepassados próximos, como é o caso, inseriam-se na cultura escrita (leitura, escrita e oralidade) no seu cotidiano.

Dessa forma, enquanto pesquisadores, alguns questionamentos nos movem: o que levou um comerciante, com pouca escolarização a fazer uso regular da escrita e de cálculos contábeis e ainda registrá-los em um livro? Que estratégias eram utilizadas para realizar os registros escritos e os cálculos que aparecem no livro? O que revelam esses registros? Esses "achados", nessa representação da escrita não escolar, podem de alguma forma memorar o passado da família do primeiro autor? Esses "rastros" retratam onde vivem, como vivem e como se relacionam com o escrito nesses contextos?

A sustentação teórica desse trabalho, apoia-se principalmente no conceito de "cultura escrita" que segundo Galvão:

[...] é o lugar - simbólico e material - que o escrito ocupa em/para determinado grupo social, comunidade ou sociedade. Essa definição baseia-se na acepção antropológica de cultura, considerada como toda e qualquer produção material e simbólica, criada a partir do contato dos seres humanos com a natureza, com os outros seres humanos e com os próprios artefatos, criados a partir dessas relações. (GALVÃO, 2010, p. 218).

É relevante considerar, também, que existem diversas modalidades de uso da escrita, como afirma e aborda em seus estudos Viñao Frago (1999) "Si han existido y existen diversas modalidades de lectura es, em parte, por han existido y existen diversas modalidades de escritura" (FRAGO, 1999, p. 288). Então, acreditamos que a finalidade desse caderno/livro de registro é administrativa, conceituada como: "El administrativo em sus diversas formas, 
desde la orden o privilegio reales hasta lo que se há dado em llamar "literatura gris" (formulários, impressos, instancias, certificaciones, instrucciones, laborales, etc.).” (FRAGO, 1999, p. 291)

Destacamos que casas comerciais, principalmente naquela época faziam uso de vários recursos para registro escrito, visto que não havia todos os aparatos tecnológicos que existem atualmente. Desta forma, deveriam existir outros suportes que serviam de registros de compras a prazo de clientes "cadernetas de contas" (expressão que escutei muitas vezes na minha infância), caderno de saída de mercadorias, de entrada e saída de valores, entre outros. Contudo, só foi encontrado esse exemplar o restante deve ter sido descartado em anos anteriores.

Portanto, é possível dizer que o senhor José Francisco Meireles, mesmo tendo pouca escolarização, teve que se apropriar e adotar estratégias de escrita e de conhecimentos matemáticos para firmar-se como comerciante. Partindo desses pressupostos, a seguir, desenvolvemos a análise do livro de Entrada de Mercadorias.

\section{O livro de registro de Entrada de mercadorias}

O livro de registro de Entrada de mercadorias, objeto de estudo aqui analisado, possui capa dura (figura 1), de cor lilás mesclada com cinza (ao que tudo indica, pois está um pouco desbotada pela ação do tempo), a capa é arrematada com tecido o que o conservou em bom estado, mede $33 \mathrm{~cm}$ de altura, por $23 \mathrm{~cm}$ de largura e por $1 \mathrm{~cm}$ de espessura, tem 18 páginas (faltando as páginas 11 e 12) - na orientação retrato (ocupa toda a extensão do livro aberto).

Na capa há uma identificação (figura 1) que diz onde foi comprada, além de espaço para registro do nome da firma, endereço, número do livro e ano de uso. Esses dados estão rasurados, mas, por algum motivo, não foram preenchidos, pois aparecem apenas os rabiscos, possivelmente de uma das crianças que brincava com o suporte. 
Figura 1: Capa e identificação do livro de Registro de entrada de Mercadorias.
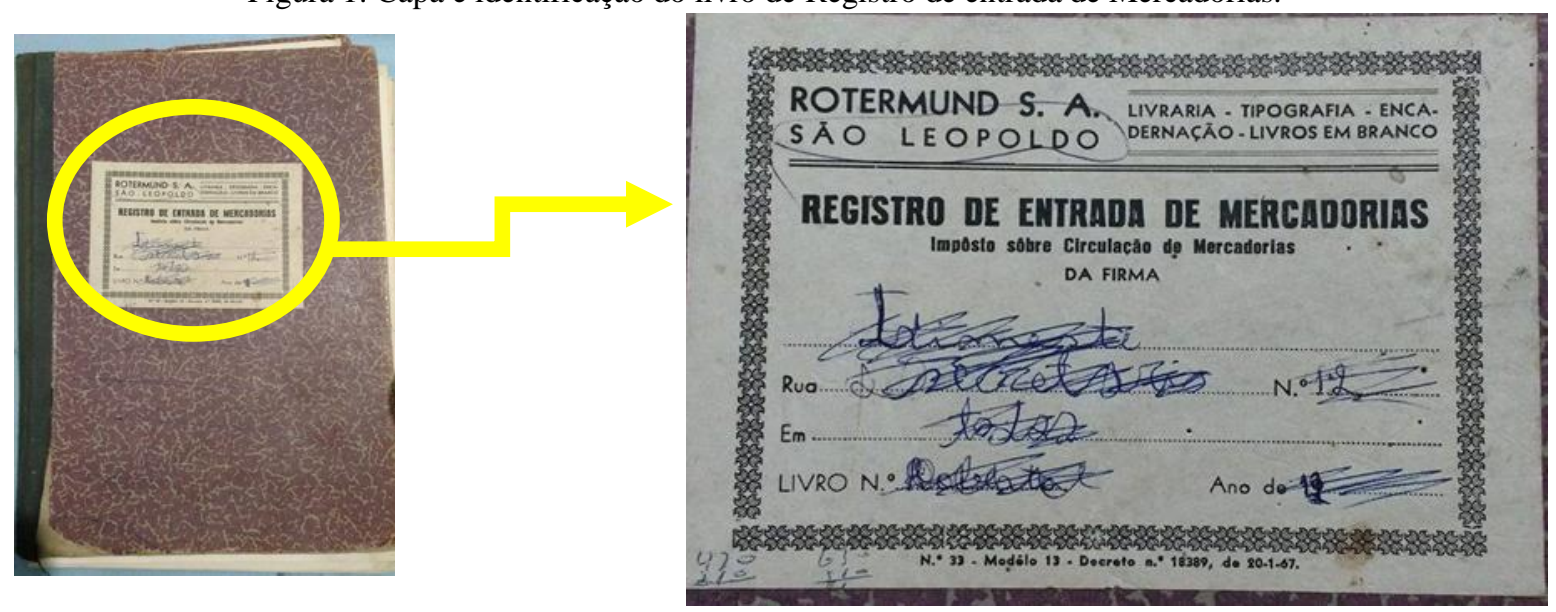

Fonte: Dos autores

Como pode ser visualizado, no papel de identificação da capa aparece a finalidade do livro, no caso, “imposto sobre circulação de Mercadorias", além do número de um decreto que normatizava a forma de registro no suporte, decreto $\mathrm{n}^{\circ} 18.389$ de 20 de janeiro de 1967. Cabe destacar que o livro apresenta uma incompatibilidade de datas, o decreto que normatiza é de 20/01/1967, a nota de abertura é de 19/08/1967 e o primeiro registro é de 03/01/1967. O único motivo lógico que encontramos para explicar tal discrepância, seria o fato dos registros serem realizados em um outro suporte e depois "passado a limpo" no livro, dessa forma, o livro pode ter sido adquirido em agosto de 1967 (data de sua abertura), posteriormente os meses anteriores foram "passados a limpo", o que justificaria também a data do decreto.

O decreto 18.389, de 20 de janeiro de 1967, que aparece na capa do material estudado, define o que é um livro de Registro de entrada de mercadoria, qual sua finalidade e normatiza como deve ser o registro:

O Livro Registro de Entradas é obrigatório para todas as empresas comerciais, estabelecido pelo Regulamento do ICMS (Imposto de circulação de mercadorias e serviços) de cada estado, com o objetivo de registrar as notas fiscais de entradas, destacando-se os ICMS incidentes pelas compras.

É destinado à escrituração dos documentos fiscais relativos às entradas de mercadorias ou bens e às aquisições de serviços de transporte e de comunicação efetuadas a qualquer título pelo estabelecimento, quando contribuinte do ICMS. (Decreto 18.389, de 20 de janeiro de 1967)

Esse livro de registro era obrigatório para todos os comércios e pelo menos um funcionário ou o próprio dono deveria ter um conhecimento mínimo de porcentagem e incidência de impostos sobre mercadoria, além da prática do registro escrito regular e cuidadoso, pois o mesmo era regido por normas fixas e passível de fiscalização. O que retrata a relação do poder com a escrita discutida por Viñao Frago (1999): 
La escritura aparece, desde su expanción, ligada al poder. Crea poder y lo acrecienta. Su difusión y empleo van unidos, además, al aumento de la complejidad organizativa de esse poder, a su expansión y necessidades de información y control. (FRAGO, 1999, p. 281)

Por ser obrigatório, de alguma forma se impunha a prática da escrita e conhecimentos mínimos de contabilidade para o preenchimento das lacunas do livro. E, como já mencionei, precisava ser uma ação cuidadosa pois recebiam visitas dos órgãos fiscalizadores, o que pode ser comprovado no termo de abertura e nas páginas 2, e 5 pela presença dos carimbos da Exatoria Estadual de Canguçu $^{7}$ e Secretaria da Fazenda Inspetoria Geral ${ }^{8}$. A figura 2 exemplifica esse fato.

Figura 2: Detalhe dos carimbos da Exatoria Estadual de Canguçu e Secretaria da Fazendo - Inspetoria Geral.
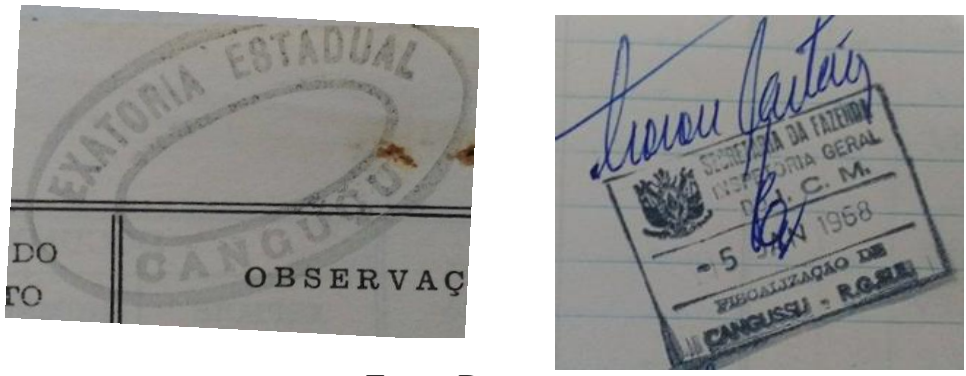

Fonte: Dos autores.

A presença desses carimbos reforça o cuidado e formalidade que deveriam ter os responsáveis pelo registro escrito e pelos cálculos no preenchimento do livro.

Em relação às pessoas que realizaram esses registros, é possível perceber 3 tipos de caligrafias diferentes. A primeira ocorre no termo de abertura, e não ocorre mais; a segunda aparece na maior parte do livro e pertence ao bisavô do primeiro autor, o que foi possível constatar por semelhança com outros documentos, entre eles uma carta testamento ${ }^{9}$ escrita e assinada por ele; a terceira caligrafia ocorre no meio do livro, páginas 10, 13, 14, 15, 16 e 17, não foi possível identificá-la com precisão, mas é possível que seja da avó do primeiro autor pela lembrança que o mesmo tem, pois sua letra chamava atenção, pois era muito bonita -

\footnotetext{
${ }^{7}$ A exatoria estadual de Canguçu esteve em atividade até o ano de 2015 e atendeu até 14 mil Produtores rurais e microempresários. Informações em <http://www.cangucuemfoco.com.br/2015/02/agencia-de-cangucu-daexatoria-pode.html>

${ }^{8}$ A Secretaria da Fazenda do Rio Grande do Sul foi criada em 21 de março de 1890, pelo Ato $\mathrm{n}^{\circ} 141$ do Governador Político do Estado, Julio Falcão da Frota. Entre suas funções está o cadastramento e fiscalização do comércio que se estabelece no Rio Grande do Sul. Informações <http://www.fazenda.rs.gov.br/conteudo/999/historico>

${ }^{9}$ A carta testamento, datada de 15 de setembro de 1970, encontra-se em posse de um sobrinho de José Francisco Meireles, o documento não teve validade jurídica, embora a maioria dos seus desejos expressos na mesma tenham sido cumpridos.
} 
Maria Izabel Meireles Soares ( $4^{\mathrm{a}}$ série primária de escolaridade) - filha de José Francisco. A figura 3 mostra o detalhe de cada uma das três caligrafias encontradas no livro.

Figura 3: Detalhe dos três tipos de caligrafias encontrados no livro, na sequência: não identificada; caligrafia do José Francisco Meireles e caligrafia, supostamente, de Maria Isabel Meireles Soares.
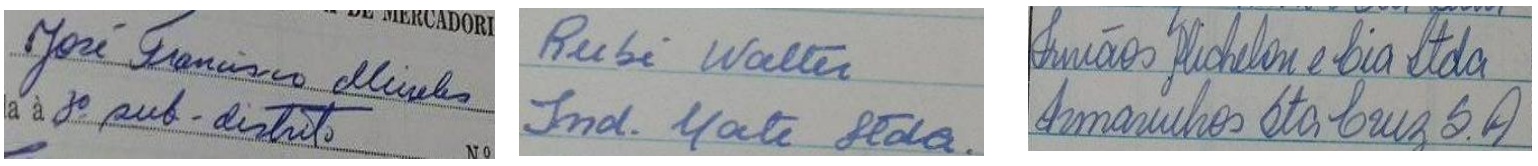

Fonte: Dos autores.

Pode-se observar que são caligrafias bem legíveis e cuidadosamente desenhadas, pois o livro não apresenta rasuras. Esse fato reforça a tese de que fosse realizado um rascunho e depois "passado a limpo" no livro, pois as orientações do decreto supracitado eram bem detalhadas e a forma de registro era chamada de "Forma de Escrituração" (Decreto 18.389, de 20 de janeiro de 1967) e deveria ser:

Escrituradas individualmente, na ordem cronológica das efetivas entradas das mercadorias no estabelecimento ou na ordem das datas de sua aquisição ou desembaraço aduaneiro, quando não transitarem pelo estabelecimento adquirente ou importador. Os registros serão feitos, documento por documento, desdobrados em linhas de acordo com a natureza das operações, segundo o Código Fiscal de Operações e Prestações - CFOP. (Decreto 18.389, de 20 de janeiro de 1967)

Tal Código deu origem a uma tabela com 6 itens, alguns deles subdivididos em outros e deveriam ser totalmente preenchidos com todos os detalhes solicitados. O registro deveria ser feito quando a mercadoria desse entrada no comércio e, mensalmente efetuado um balanço com os somatórios dos valores que deveriam ser tributados, inclusive com o cálculo e valor do que deveria ser pago de ICMS. Não podemos afirmar, pois faltam duas páginas no livro (11 e 12), mas foi possível perceber que todos os meses teve entrada de mercadorias. A figura 4 mostra a distribuição dos itens na página do livro. 
Figura 4: Página 2 do livro de registro de entrada de mercadorias mostrando a distribuição dos itens que deveriam ser

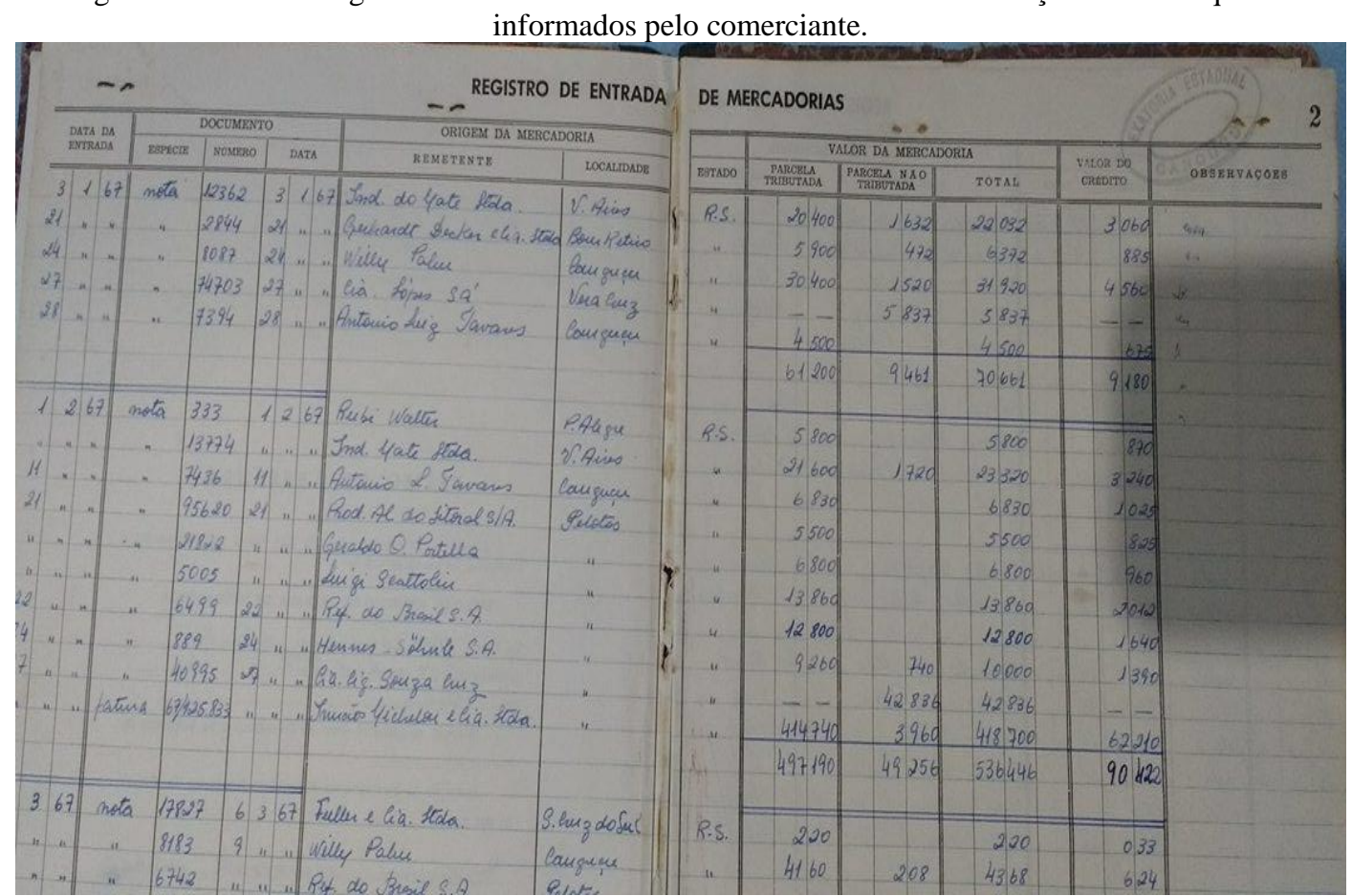

Fonte: Do autor.

O último registro é de 12/09/1971, encontra-se na última página do livro e na última linha, o que indica um uso ordenado e sequencial do suporte. Observando os registros realizados, também foi possível levantar alguns dados, entre eles que em 1967 e 1968 houve registro de entrada de mercadoria nos 12 meses; já em 1969 e 1970 - páginas faltantes - há registro de entrada de mercadoria em 8 meses em cada ano; e em 1971 há anotações referentes a 9 meses, totalizando 48 meses de registro.

No mês de agosto de 1971 aconteceu o maior movimento de entrada de mercadorias, foram 15 registros, o menor ocorreu em abril de 1968, com apenas 3 registros. O mês com maior montante de valores tributáveis é março de 1971 com 2.479,26 cruzeiros $^{10}$ com recolhimento de 345,07 cruzeiros de ICMS, ou seja, uma incidência de 13,92\% ${ }^{11}$ de tributos. O mês com menor somatório de valores tributáveis ocorreu em setembro de 1967 com 19,82 cruzeiro e recolhimento de ICMS de 2,91 cruzeiros, com incidência de 14,68\% de impostos. Não foi encontrada uma explicação para essa variação nas porcentagens, contudo há variação no índice cobrado de ICMS de um ano para o outro.

Um outro item que me chamou atenção foi a “origem da mercadoria” há registro de 15 municípios diferentes: Canguçu, Pelotas, São Lourenço do Sul, Santa Cruz do Sul, Porto

\footnotetext{
${ }^{10}$ Em 1967 começa a vigorar o Cruzeiro novo no Brasil, há um retorno no uso centavo no sistema monetário brasileiro. Em 1971 retorna o Cruzeiro e o centavo é mantido. As cédulas e moedas foram substituídas gradativamente, mas a forma de registro continuou sendo a mesma.

${ }^{11}$ Calculado pelo autor - (aproximadamente).
} 
Alegre, Arroio dos Ratos, Cachoeira do Sul, Encruzilhada do Sul, Camaquã, São Leopoldo, Campos Quevedos, Lajeado, Ijuí, Bom Retiro e Venâncio Aires. O registro escrito propiciou um conhecimento maior dos seus fornecedores, da origem das mercadorias e porque não dizer conhecimento do seu entorno, dos seus municípios vizinhos e alguns nem tão vizinhos assim, como é o caso de Porto Alegre e Arroio dos Ratos.

Além da grande quantidade de números, símbolos monetários e datas, no livro a escrita é bem presente, todas as páginas são repletas de nomes de cidades, empresas e descrição de mercadorias.

Para Hébrard (2000, p. 38), esses registros “escapam” da formalidade, pois além de cumprir sua finalidade administrativa/burocrática, também, apresentam situações da vida cotidiana, nesse sentido, "são atos próximos e que progressivamente se confundem". Ainda conforme as palavras do autor:

Prestar contas de suas despesas ou de sua vida são atos próximos e que progressivamente se confundem. O espaço gráfico do registro, em partida dobrada, revela-se um lugar onde as ordens estritas oferecem múltiplas possibilidades para 'pôr em ordem' os atos dispersos da existência (HÉBRARD, 2000, p.39).

Como já foi dito, além dos números há registros de endereços, nome dos donos das empresas fornecedoras e em alguns caso até o telefone. Entendo que dessa forma, além de cumprir a "obrigatoriedade" exigida pela legislação a escrita é usada como suporte para lembrança de informações importantes para o comércio. Assim, possivelmente, um fornecedor de um produto que teve boa aceitação pelos clientes, seria facilmente encontrado através do registro realizado no livro que não poderia ser perdido ou extraviado, um suporte seguro para tais informações.

Finalizando, como já mencionamos anteriormente, o nível de escolaridade dos escreventes era baixo e, mesmo assim, há poucos erros de escrita em seus registros, o que revela um esforço para fazer uso da escrita da maneira correta, visto que, estavam lidando com um documento que exigia formalidade, o que de certa forma contribuía, também para o treino da escrita. A necessidade do registro fez com que os envolvidos mantivessem uma prática cultural mesmo que para escrever questões voltadas à contabilidade e balanço do estabelecimento comercial.

\section{Considerações finais}

Com a descrição de um suporte de um livro de entrada de mercadorias buscamos responder às indagações propostas no início do trabalho: o que levou um comerciante, com 
pouca escolarização a fazer uso regular da escrita e de cálculos contábeis e ainda registrá-los em um livro? Que estratégias eram utilizadas para realizar os registros escritos e os cálculos que aparecem no livro? O que revelam esses registros? Esses "achados", nessa representação da escrita não escolar, podem de alguma forma memorar o passado da família do primeiro autor? Esses "rastros" retratam onde vivem, como vivem e como se relacionam com o escrito nesses contextos?

É possível considerar que por mais que existam referenciais teóricos para embasar o trabalho que aqui apresentamos, ainda existe dificuldade em analisar esse tipo de material. Meu esforço foi para mostrar, nesse ensaio, ainda que de maneira superficial, que um comerciante, com pouca escolarização, adquiriu habilidade de preencher um documento livro de entrada de mercadorias - ou seja, fez uso da escrita e da matemática para atender as suas necessidades. Desta forma, estava inserido nas "culturas do escrito" (GALVÃO, 2010) e fazia uso da escrita.

José Francisco Meireles, mesmo tenho pouca escolarização, como comerciante precisava obedecer a legislação vigente apresentando a documentação necessária para manter sua casa comercial aberta e dentro dos padrões exigidos. Desta forma, apropriou-se das normas, e possivelmente mais tarde tenha ensinado a sua filha Maria Izabel Meireles Soares que, então, passou a preencher o livro de entrada de mercadorias. Os registros revelam que as orientações para o preenchimento do livro foram cuidadosamente respeitadas, pois não aparecem rasuras na escrita original. Por isso, acredito que algumas estratégias possam ter sido utilizadas para isso, entre elas que escrita tenha sido realizada primeiro a lápis e posteriormente passada à caneta ou também que tenha sido realizado um registro inicial em outro suporte (rascunho) e depois passado para o destino final/livro.

Através dos registros foi possível constatar que, mesmo vivendo na zona rural, distante da cidade, o comércio proporcionava o contato com diferentes pessoas, que residiam em no mínimo - segundo registro do livro - 15 municípios diferentes. Para nós, enquanto pesquisadores, sobretudo o primeiro autor, como bisneto de José Francisco foi possível conhecermos e nos aproximarmos um pouco mais da sua história, conhecendo também atividades do seu cotidiano e suas formas de inserção na cultura escrita.

\section{Referências}

Decreto $\mathrm{n}^{\circ} 18.389$ de 20 de janeiro de 1967. Disponível em http://www.portaldecontabilidade.com.br/obrigacoes/livroregistroentradas.htm (consultado em 20 de março de 2017). 
FRAGO, A. V. Leer y Escribir. Historia de dos prácticas culturales. México. Fundación Voces y Vuelos, 1999.

GALVÃO, A. M. de O. Oralidade, Memória e a Mediação do outro: práticas de letramento entre sujeitos com baixos níveis de escolarização - o caso do cordel (1930-1950). In: Revista Educ. Soc., Campinas/SP, vol. 23, n. 81, p. 115-142, dez. 2002.

GALVÃO, A. M. de O. História das culturas do escrito: tendências e possibilidades de pesquisa. In: MARINHO, Marildes, CARVALHO, Gilcinei (orgs.). Cultura escrita e letramento. Belo Horizonte: Autêntica, 2010.

HÉBRARD, J. Por uma bibliografia material das escrituras ordinárias: a escrita pessoal e seus suportes. Refúgios do eu: Educação, História, Escrita autobiografica/Mignot, A . C.V; Bastos, M.H.C. , Cunha,M.T.S.(orgs). Florianópolis: Mulheres,2000. p. 29-61. 